\title{
The Student's Conflict Resolution in Individual Psychological Dynamics
}

\author{
Budi Purwoko \\ Departement of Guidance and Counseling \\ Universitas Negeri Surabaya \\ Surabaya, Indonesia \\ budipurwoko@unesa.ac.id
}

\begin{abstract}
This article aims to describe the factors that cause conflict, how the process of conflict and the solution of the conflict in the framework of individual psychological dynamics. This qualitative research analyzes conflict case data with selected references to answer the focus of the study. Ten cases of interpersonal conflict were chosen which included destructive conflict and constructive conflict. Conflict actors are interviewed in-depth based on the focus of the study. Conclusion (1) Conflict is caused by differences of opinion, misunderstandings, actions that are considered detrimental to others, and feelings of being too sensitive to negative thoughts. Conflict is triggered by differences in views and perceptions that are prevented from achieving goals; (2) Three focus views on conflict include (a) perceptions of the problem of conflict, (b) perceptions of objectives, and (c) perceptions of the perpetrators of the conflict; (3) Understanding of conflict is formed by the reality of the object and the individual's perception of conflict. (4) the psychological dynamics of conflict are described in the $\mathrm{ABC}$ triangle, as a series of mutual influences between Attitudes + Behavior + Contradiction.
\end{abstract}

Keywords—students; conflict resolution; psychological dynamics

\section{INTRODUCTION}

In general, conflict solution programs tend to manipulate the external aspects of the source of conflict without touching the root of the real conflict [1]. The learning positive ways to deal with conflict are important to develop. In school, how to resolve conflicts often uses "punishmentbased". The ways to deal with conflict depend on how individuals view a conflict. If the conflict is perceived negatively, it will affect the attitudes and behavior of destructive-dysfunctional conflict resolution. Conversely, a positive perspective on conflict shapes attitudes and behavior in constructive-functional conflict resolution [2]. Facilitating individuals in getting positive perspectives and perceptions of conflict events is an important focus in shaping attitudes and behaviour in constructive-functional conflict resolution [2][3].

During this time, we base the views conflict solution on external factors in the form of social subsystems. The solution to conflict according to macro theory manipulates external aspects in the form of economic, social, political, military (security), religious, and other aspects [3]. Current conflict resolution focuses on efforts to prevent conflict through educative, cultural, and pedagogical methods. This program applies the theory of micro conflict with a focus on studying how the psychological dynamics of individuals face conflict [4]. The way of intervention is the manipulation of aspects of understanding, perception, attitude, and mastery of constructive conflict resolution skills. The application of this program is educational, training, learning activities that enhance individual skills in constructive conflict resolution. This reasoning underlies the importance of studying the concept of individual psychological dynamics in dealing with conflict, which is used as a reference for cognitive, affective, and individual behavioral interventions in the face of conflict [5].

Conflict starts from the individual's external condition. But actually, the external cause is neutral. Intangible internal factors of individual psychological dynamics are reactions to external factors, a neutral conflict event. Perceptions, feelings, responses, needs, motivations, and attitudes of individuals are internal factors that determine how to deal with conflict. Internal factors are the basis of the pattern of the solution to the conflict. There are two forms of "perception" that direct "attitudes and behavior" in responding to conflict, namely competitive perception and cooperative perception. Competitive perception makes opposing attitudes with conflict responses defeat others (win-lose paradigm). Cooperative perception makes the attitude of collaboration with conflict response compromise and collaboration (win-win paradigm). Individual perceptions determine attitudes and behavioral responses to conflict. Perception is a person's perspective on the source of conflict. Pattern The solution to conflict comes from the dominance of competitive perception or cooperative perception [6].

The attitude element reflects the choice of individuals in positioning themselves in the face of conflict whether opposing and defeating or otherwise being cooperative and respectful. The tendency of positive or negative attitudes to conflict is determined by individual perceptions, whether collaborative or competitive perceptions. Furthermore, attitudes appear in individual behaviour. A positive attitude faces tangible conflict in the behaviour of win-win conflict 
resolution [7]. Parties to the conflict try to solve problems with the orientation of meeting common interests, fostering cooperation, acting constructively and creatively. Such conflict responses are termed constructive and functional conflict responses. Conversely, negative attitudes in behavioural conflict win themselves and defeat opponents, achieve unilateral gains, destruction/obstruction of the interests of opponents, disputes, and fights. Such conflict responses are termed destructive and dysfunctional responses [8]. Conflict and destructive conflict solutions can be prevented early if the internal psychological dynamics of an individual are identified. How is the process of perception, how the process of attitude, how the response of behaviour of conflict and the interaction between the three factors is the focus of this article.

\section{METHOD}

The design of this study is qualitative, by analyzing the results of conflict case data with selected libraries [9]. Qualitative analysis - the analysis of textual, visual, or audio data-covers a spectrum from confirmation to exploration [10]. Ten cases of interpersonal conflict were chosen which included destructive conflict and constructive conflict. Conflict actors are interviewed in-depth based on the focus of the study. Data from interviews were analyzed and discussed to answer the focus of the problem. The focus group discussion technique is applied by involving researchers, conflict participants, and experts.

\section{RESULTS AND DISCUSSION}

\section{A. Causes of Conflict}

Conflict is a clash, discrepancy, hostility, fighting, opposition, and antagonistic interactions. Conflict means "A fight; a collision; a struggle; a contest; a position of interest, opinion or purposes; mentally strife; agony ". Conflict is also interpreted as a fight between what is expected by someone with the reality achieved. Conflict is a difference in objectives, conflicts of interest, and obstruction of meeting needs. Conflict is antagonistic psychological relations concerning irreconcilable goals, hostile emotional attitudes, and different value structures [11]. If a person's actions in fulfilling and maximizing their needs and objectives hinder or make the actions of others ineffective, a conflict ensues.

Based on the symptoms, there are two conflict triggers, namely different views and conflicting views. Conflict is also triggered by (1) differences of opinion, each of which considers the most correct, (2) misunderstandings, (3) actions that are considered detrimental to the other party, and (4) feeling too sensitive that leads to negative thinking [11]. Conflict is also caused by poor communication. Misunderstandings can make opposition. Ideas must be conveyed appropriately and ethically. In interpersonal communication, someone needs to master how to empathize, listen to others, open up, express ideas and feelings well. Being yourself effectively in communication can avoid conflict [12]. There are still many people who feel satisfied that they have won and defeated others
Competitive attitude paradigm is win-lose to overcome differences giving birth to conflict. Coercion of desire in others, rejecting different perspectives, closing themselves, and rigid perspectives reinforce negative conflicts.

The conflict and its causes can be classified in the form of (1) controversy, that is when ideas, information, conclusions, opinions of a person are not in accordance / contradictory / do not match with others; (2) conceptual conflict, which is when ideas conflict between individuals and others. Information received is perceived as contrary to what was previously known; (3) conflicts of interest and interests, when a person's actions in achieving their objectives are found to hinder or interfere with the efforts of other parties in achieving their goals; (4) developmental conflicts, when the actions of adults and children are contradictory due to incompatibility of thoughts, attitudes, and behaviour [7][13].

\section{B. Perception of Conflict}

Individual perception of conflict is what is thought so that it forms a perspective that leads to the choice of attitude in the face of conflict. Views of conflict are influenced by experience, knowledge, and values that someone internalizes 15 . Three things affect perceptions including (1) perceptions of the problem of the conflict itself; (2) perceptions of goals; (3) perceptions of who the conflict is. The form of conflict appears in verbal and non-verbal behaviour, including in the form of actions that harm, demean, and hinder one's goals. Conflict behaviour is manifested in interactions that are marked by strife, cursing, mocking, indifference, gossiping, hitting, damaging, withdrawing, and others. Often conflict actors pay more attention to the form of conflict that arises and appears on the surface. It is rare for actors to pay attention to why conflict can occur. When attention and solutions lead to the behaviour of the conflict that appears, precisely the conflict will spread to both the actors, the region and the root of the problem.

Perception of goals is how individuals see the goals, desires, and expectations of the parties involved in the conflict [14]. Often observations of goals are ignored, whereas conflict actors focus more on behaviours that appear as antagonistic verbal and non-verbal responses. The cases in this study, individuals prioritize achieving their own goals, while the goals of other parties are rarely understood. This perspective of egocentrism gives birth to a justification for oneself while the other party is considered wrong. When the perspective is dominated by the presumption of the most correct, it will trigger an attitude of coercion and defeat the other party. Egocentrism, selfjustification, and own goal orientation increase the conflict that worsens [13] [15].

Perception of perpetrators of conflict is how individuals place themselves concerning other parties. There are two patterns of relationships, namely as "opponent" or "friend" figure. The figure of "opponent" puts the other party as the party that must be defeated, while the figure of "friend" puts the other party as the party that still needs to be maintained. The "friend" figure in the case in this study was represented 
by the boyfriend, relatives in the family, people who had done good. But there are extreme and unique cases, namely a teacher, a father, and a friend who is seen as an "opponent" figure. This fact reflects the perception of the other party to connect it with the appreciation of the problem and its purpose in the conflict that occurred [13].

The three domains of focus on individual perceptions are interconnected and related, to crystallize in an individual stance point in taking steps to resolve the conflict. In general, the individual attitude points summarized in the three conflict resolution paradigms include (1) the losinglosing paradigm; (2) the paradigm of losing-win / win-lose; and (3) the win-win paradigm. The choice flow of conflict solutions stems from how individuals conclude their perceptions of the problem of conflict, goals, and parties involved in the conflict [16].

\section{Factors that Influence Perceptions of Conflict}

Individual perception is the result of individual thinking towards the object of perception. Individual appreciation of the object of observation is shaped by the reality of the object and reality individual itself. The reality of the object, in this case, is who the parties involved in the conflict, how the problem, how the context that accompanied the conflict, and the consequences of the conflict [17]. Individual reality includes understanding, experience, and individual values that impress the reality of the object. How individuals think about the reality of the object of conflict is unique and subjective according to their reality. Who is the party involved in the conflict has a certain impression for the individual? Will it be suggested as a party that must be respected, loved, and needs to be maintained? On the contrary, is it suggested that the party must be opposed, defeated, and as a party that does not need to maintain its relations of relations [6].

The conflict context is the scope of the conflict including where, when, who, what, and how the conflict. The scope of the conflict relates to how important the object of the conflict is, who are the other people around the conflict, what other problems around the conflict [15][13]. As a result of conflict is the risk caused by conflict on the actors and the environment of the perpetrator. Often the consequences of conflict are lived out unilaterally and are oriented towards themselves rather than on the side of themselves and other parties in a balanced manner. The reality of the individual's perspective is shaped by his understanding, experience, and values. Understanding is the knowledge that is owned, while the experience is the conceptualization of past events both about themselves and others 18. Self-values are words of heart that reflect the morality and social values in guiding choices should or should not be done.

\section{Perception, Attitude, Motivation, and Direction of Conflict Resolution in the Context of Individual Psychological Dynamics}

Individual internal psychological dynamics in dealing with conflict are modelled in ABC triangles, Attitudes + Behavior + Contradiction. Contradiction (C) is a manifestation of conflict in the form of resistance between one individual and another. The root of the conflict is the conflict of objectives and intentions that are not by one another [18][19]. Based on the cases in this study, the root of the conflict included differences of views, principles, values, and goals that were blocked by others. Parties that can be perceived as barriers include parents, teachers, family members, friends, girlfriends. Problems can come from personal, social, academic, or a combination of several types of problems [15], [6].

The component "attitude" (A) represents the way the conflicting parties feel and think. Attitudes are determined by how individuals perceive which includes: perceiving themselves and others, perceiving problems, and perceiving goals. Self-perception in the form of a way of seeing himself as someone meaningful with other parties or not meaningful with other parties. How to perceive "other parties" whether by respect and love or by humiliation and hatred. The way to perceive referring problems includes problems with the context of the problem [20]. The way to perceive goals includes the expectations and desires of themselves and others. From the cases analyzed how to perceive oneself related to harassment, lower self-esteem, values, and principles tend to trigger high antagonistic attitudes. Another way of perceiving when seen as a figure that must be respected loved also influences the direction of the solution. Conversely, antagonism increases if the other party is seen as a guilty party that must be defeated [20].

Individual ways of thinking, forming attitudes, stimulating motivation to act, and directing behaviour in solutions to certain conflicts. This pattern runs linearly with each other as a cause and effect. The component "behaviour" represents a way of acting during conflict whether trying to find common interests, acting constructively and creatively, or acting in a way that is harmful and hurts the other. Behaviour is determined by ways of behaving that are guided by perceptions and ways of thinking. From the cases in this study, the attitude of hating and destroying others drives confrontational behaviour overcoming the other or a losing-win solution. Some of them build compromise solutions when individuals do not perceive themselves as people who are harassed by their pride [18][19].

Furthermore, the three SPP triangle angles stimulate each other so that at a certain level crystallizes around the pole "Friend/Self" and can be at the poles "Opposite/Other". The "Friend/Self" pole is a manifestation of positive attitude and behaviour, while "Opponent/Other" manifests as a negative element.

\section{E. Factors that Strengthen the Solution to Destructive Conflict}

The solution to destructive conflict paradigms "winlose" or "lose-lose". Win-lose paradigm through competition and confrontation to defeat other parties. The losing-losing paradigm is by avoiding conflict and allowing problems to occur as they are [18][21]. The destructive conflict will occur, marked by the following [7] [6]. 
1) Each party to the conflict is considered to have hampered hopes, desires, needs and was recognized as a threat that gave birth to frustration. The more important the needs are inhibited [6], the stronger the frustration that is generated. High and low frustration is linear with attempts at aggression as a form of destructive solutions.

2) The parties to the conflict consider it not important to maintain relations between them.

3) The source of conflict is related to self-values, selfprinciples, self-esteem, self-identity, and raises the assumption of indecency by other parties.

4) The root of conflict comes from the vital interests that determine the survival of the community.

5) Conflict is considered to be finished well through selfvictory.

6) Low understanding of sources of conflict, conflict issues, and ways of solutions.

7) Prioritizing strength, power, high self-esteem, and low respect for others.

8) Individual experiences characterized by a competitive atmosphere, confrontation, and conflict.

9) Individuals who consider themselves weak, tend to succumb and withdraw from conflict.

The form of a destructive conflict solution is patterned in two paradigm trends, namely losing-winning and losinglosing. The winning losing way is in the form of intimidation, other crediting, arguments, and physical fights. All of these actions try to defeat your opponent and win yourself. The losing-losing paradigm is approached by ignoring self-interest or succumbing, avoiding the reality of conflict, and allowing it to happen as it is without action [6], [22].

\section{E. Factors that Strengthen the Solution to Constructive Conflict}

Constructive conflict resolution uses the win-win paradigm, by compromise and collaboration, which seeks to fulfil the goals of both parties through agreement and trying to maintain the continuity of relations $2,8,19$. The way constructive solutions will be chosen if,

1) The relationship between the two parties is considered important to be maintained.

2) Having good intentions to resolve conflicts through dialogue in collective deliberations.

3) Can be well understood the source of the problem of conflict and the objectives that are considered obstructed.

4) Problems are not sourced from very vital interests which are considered by both parties.

5) Prioritizing the maintenance of relations and fulfilling the objectives of both parties.
6) Good understanding of the source of conflict, conflict issues, and the solution.

7) Dominated by values of appreciation on the other side.

8) Individual experiences are characterized by a collaborative and peaceful atmosphere.

The form of a constructive conflict solution is a win-win paradigm. The method used is through increasing communication, negotiation, mediation, deliberation, and discussion of common problems. Each party tries to control itself and is based on appreciation to the other party

\section{CONCLUSION}

Conflict is caused by differences of opinion, misunderstandings, actions that are considered detrimental to others, and negative feelings of sensitivity. In general, conflict is triggered by differences in views and obstruction of achieving goals. Individual perceptions of conflict are what is thought so that it forms a perspective that guides him to choose attitudes and behaviors in dealing with conflict. The way of thinking is related to experience, knowledge, and internalized values. Perception of conflict includes (1) perception of the problem of the conflict itself; (2) perceptions of inhibited goals and interests, perceptions of who the conflict is.

Understanding of the object of conflict is formed by the reality of the object and the reality of the individual itself. The reality of the object includes who the parties to the conflict, the problem and the context of the problem, and the consequences of the conflict. Individual reality includes understanding, experience, values that impress how the reality of an object.

The internal psychological dynamics of an individual in the face of conflict can be categorized into three integrated parts including the components of the $\mathrm{ABC}$ triangle, which designate Attitudes + Behavior + Contradiction. Destructive conflict is carried out with the win-lose paradigm and the losing-losing paradigm. The win-lose paradigm is carried out by competition and confrontation. While the way to lose, and lose is done by avoiding conflict and allowing problems to occur as they are. Constructive conflict through win-win methods based on respect for other parties, prioritizing collective agreements, maintaining harmonization of relationships, achieving mutually agreed goals. The implementation is carried out through improved communication, negotiation, mediation, deliberation, and discussion of common problems.

\section{REFERENCES}

[1] J. S. Himes, Conflict and conflict management. University of Georgia Press, 2008.

[2] M. Deutsch, "Cooperation and competition," in Conflict, interdependence, and justice, Springer, 2011, pp. 23-40.

[3] L. Kriesberg, Constructive conflicts: From escalation to resolution. Rowman \& Littlefield, 2007.

[4] R. Collins, Violence: A micro-sociological theory. Princeton University Press, 2009.

[5] D. Crawford, Conflict Resolution Education: A Guide to Implementing Programs in Schools, Youth-Serving Organizations, \& 
Community \& Juvenile Justice Settings. DIANE Publishing, 1996.

[6] M. Deutsch, "Constructive conflict resolution: Principles, training, and research,” J. Soc. Issues, vol. 50, no. 1, pp. 13-32, 1994.

[7] M. Deutsch, P. T. Coleman, and E. C. Marcus, The handbook of conflict resolution: Theory and practice. John Wiley \& Sons, 2011.

[8] Y. F. Leung, "Conflict management and emotional intelligence," 2010.

[9] A. Strauss and J. Corbin, Basics of qualitative research techniques. Sage publications Thousand Oaks, CA, 1998.

[10] P. Mihas, "Qualitative data analysis," in Oxford Research Encyclopedia of Education, 2019.

[11] H.-W. Jeong, Conflict management and resolution: an introduction. Routledge, 2009.

[12] S. Mitkus and T. Mitkus, "Causes of conflicts in a construction industry: A communicational approach," Procedia-Social Behav. Sci., vol. 110, pp. 777-786, 2014.

[13] B. Purwoko, "KONSELING RESOLUSI KONFLIK UNTUK MENINGKATKAN PERSEPSI POSITIF TERHADAP KONFLIK DAN SIKAP KOLABORATIF PADA SISWA," Elem. Islam. Teach. J., vol. 3, no. 2, 2015.

[14] R. J. Robinson, D. Keltner, A. Ward, and L. Ross, "Actual versus assumed differences in construal:" Naive realism" in intergroup perception and conflict.," J. Pers. Soc. Psychol., vol. 68, no. 3, p. 404, 1995.

[15] B. Purwoko, "Keefektifan Konseling Resolusi Konflik untuk Mengatasi Konflik Interpersonal pada Siswa SMA," DISERTASI dan TESIS Progr. Pascasarj. UM, 2015.

[16] B. Purwoko, "Pengembangan Buku Paket Bimbingan Kecakapan Menyelesaikan Konflik Interpersonal Secara Konstruktif Bagi Siswa SMA.(Tesis)," DISERTASI dan TESIS Progr. Pascasarj. UM, 2009.

[17] F. Bilqis, "Hubungan Antara Persepsi Dengan Cara Penyelesaian Konflik Interpersonal Pada Siswa Kelas XI Jurusan Akuntansi SMK Mahardhika," J. BK UNESA, vol. 3, no. 1, 2013.

[18] J. Galtung, "Theories of conflict," Defin. Dimens. negations, Form. Oslo Transcend, 2009

[19] J. Galtung, Conflict transformation by peaceful means: The Transcend method. UN, 2000.

[20] M. B. Brewer, "The psychology of prejudice: Ingroup love and outgroup hate?," J. Soc. Issues, vol. 55, no. 3, pp. 429-444, 1999

[21] O. Ramsbotham, Transforming violent conflict: Radical disagreement, dialogue and survival. Routledge, 2010.

[22] J. Galtung, "Institutionalized conflict resolution: A theoretical paradigm,” J. Peace Res., vol. 2, no. 4, pp. 348-397, 1965. 